УAK 316.334.3

ББК 66.3(0), 4

DOI 10.22394/1682-2358-2021-6-102-110

V.A. Podolsky, Candidate of Sciences (Politics), Docent at Political Sciences Faculty, State Academic University for the Humanities

\section{SOCIAL POLICY DEVELOPMENT IN THE USSR: COMPARATIVE ANALYSIS WITH WESTERN PRACTICES}

The origins and development of the social support system in the USSR: introduction of the pensions, free healthcare, and free education are analyzed. The study shows, how the Soviet system developed the German corporate ideas of insurance, borrowed by the Russian Empire, and then adopted the British universalistic approach in the second half of the $\mathrm{XX}$ century.

Key words and word-combinations: social policy, pensions, history of the USSR, foreign experience.
В.А. Подольский, кандидат политических наук, дочент факультета политологи Государственного академического университета гуманитарных наук (email: deomniscibili@yandex.ru)

\section{РАЗВИТИЕ СОЦИААЬНОЙ ПОАИТИКИ В СССР:

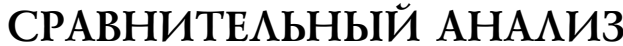 С ЗАПААНЫМИ ПРАКТИКАМИ*}

Аннотация. Анализируются возникновение и развитие системы социальной поддержки в СССР: введение пенсий, бесплатного здравоохранения, бесплатного образования. Показано, как в советской системе развивались немецкие корпоративные идеи страхования, заимствованные Российской империей, а во второй половине $\mathrm{XX}$ в. - британский универсалистский подход.

Ключевые слова и словосочетания: социальная политика, пенсии, история СССР, зарубежный опыт.<smiles>[AlH2]</smiles>

зучение советской соџиальной политики важко по трем причинам. Вопервых, социальная подАержка в исторической митературе и массовом сознании обычно воспринимается как самый УАачный элемент организации советско-

* Исследование выполнено при финансовой поддержке в рамках ГЗ (государственного задания) ГАУГН № FZNF-2020-0014 по теме «Современное информационное общество и цифровая наука: когнитивные, экономические, политические и правовые аспекты». 
го общества. Сравнение с зарубежными практиками позволит оценить эффективность советской соџиальной подАержки. Во-вторых, современная российская система социальной политики во многом основана на советских практиках, но заметно отличается от прошиой системы. На Западе в 1980-е годы происходияа трансформация социальной подАержки, хотя, как и в России, общие особенности соџиальной политики сохранились. Рассмотрение изменений в соџиальной сфере западных стран позволит понять цогику преобразований, произошеАших в постсоветской России. В-третьих, в научной митературе обычно

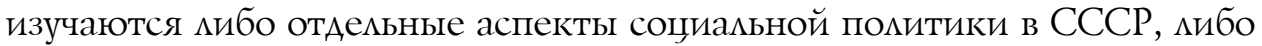
предлагаются общие обзоры, в которых не принимаются во внимание значимые эмементы советской соџиальной подАержки.

Советская соџиальная политика активно изучалась и в советский период, и в современной России. ОАин из первых теоретиков и систематизаторов права соџиального обеспечения в СССР - В.С. Анареев, сотрудник Всесоюзного юридического заочного института [1] . Из работ постсоветского периода Аостаточно значимыми явмяются труды преАставителей саратовской научной школы социальной политики поА редакцией Е.Р. Ярской-Смирновой и П.В. Романова [2]. Аиссертация А.А. Гуменюка представцяет собой наиболее полное обзорное исследование по Аанной теме [3]. Последовательное сравнение становления советской и запаАной систем соџиальной политики позволит преАставить целостную картину и выявить основные особенности государственной социальной подАержкки в СССР.

История соџиальной политики в Советском Союзе может быть поАразделена на два периода: с 1917 по 1956 и с 1956 по 1991 г. В первый период система развивалась по немецкой корпоративной страховой модели на базе тех институтов, которые были созданы еще в Российской империи. Во второй период в Советском Союзе в жизнь воплощамась солидаристская модель, принятая в Британии в 1940-е годы.

Меры социальной политики начинают активно внедряться в стране сразу после прихода к власти большевиков. ОАним из первых декретов новой вмасти 14 ноября 1917 г. был учрежден Народный комиссариат государственного призрения, который взял на себя ответственность за функции и имущество бывших благотворительных обществ [4, с. 127-138] . 22 декабря 1917 г. принимается Аекрет ВЦИК «О страховании на случай болезни», который расширял право на отпуск Амя беременных женщин, существовавшее еще с 1912 г. [5, с. 199206], что стало передовым явлением дмя этого времени: в Британии закон об опмачиваемом отпуске мия матерей был принят мишь в 1975 г. [6, р. 57] , а в США не существовало федерального закона об отпуске Аля матерей до 1993 г. [6, р. 148]. 
С июля 1918 г. началось создание первой в мире централизованной бесплатной системы здравоохранения на базе мечебных учреждений и больничных касс преАприятий поА руководством народного комиссара здравоохранения Н.А. Семашко. Из-за дефицита ресурсов местных властей в 1920-е годы услуги часто оказывацись за Аеньги, но Аоступность и качество медицинских услуг постепенно возрастали. Численность врачей в РСФСР выросла с 16 тыс. в 1917 г. до 90 тыс. в 1930-е и до 470 тыс. в 1970-е годы [7, с. 372-429].

Ожидаемая продолжительность жкизни в России в начале XX в. в 1,5 раза уступала развитым странам и составмяла 30 мет против 45 мет в Европе. К 1960-м годам продолжительность жизни в РСФСР выросла вдвое, до 65 мет, и почти сравнямась со средними показатемями западных стран [8, с. 95]. В Германии система здравоохранения выстраивалась вокруг больничных касс, оплачивавших медицинские услуги, куда рабочие с 1880-х годов обязывались вносить взносы. Эту архитектуру заимствовала Британия в 1910-е годы, а в 1940-х в ней была создана всеобщая система зАравоохранения с единым страховым фондом [9, р. 278].

Аекрет Совета народных комиссаров РСФСР от 5 июня 1918 г. передавал все образовательные учреждения Советской России Народному комиссариату просвешения [5, с. 358], а в октябре 1918 г. было утверждено Положение о единой трудовой школе. В стране было введено бесплатное начамьное образование [5, с. 1026-1030], которое в 1930 г. стало обязательным; уровень грамотности возрос с приблизительно с 30\% в 1916 г. до 90\% к 1940-му [10, с. 352]. Обучение в 8-10 классах с 1940 по 1956 г. было платным; стоимость обучения за год составляма порядка половины средней месячной заработной пматы. Высшее и среднее специальное образование в СССР также бымо платным до 1956 г., стоимость составцяла порядка одной месячной зарпиаты за гоА обучения [11, с. 341-345].

В Европе обязательное школьное образование было введено гораздо раньше - в XVIII в. - в Пруссии, в 1891 г.- в Британии [12, р. 151] . Хотя бесплатные места Аця некоторых студентов в западных и российских университетах предоставцялись еще в XVIII-XIX вв., в Британии высшее образование было беспиатным в 1960-1990 гг. [13, р. 92] , в Германии - с 1970-х годов [13, р. 122].

Аетские сады в 1920-е годы создавались в СССР под руководством Аошкольного отдела Народного комиссариата просвешения. В 1924 г. в них насчитывалось 270 тыс. воспитанников, 1 млн - в 1940, 12 млн - в 1970е годы $[14$, с. $53-54]$. Пцата за детский сад в советское время составмяла в среднем 1/10 от средней по стране заработной платы [1, с. 302] с Аифференциацией и мьготами в зависимости от дохода и статуса гражАан 
[1, с. 94]. Во Франщии и Италии [15, р. 72] детские образовательные учреждения стали бесплатными в 1960-е годы.

Система детских домов успешно решила проблему социализации сирот благодаря методу педагога А.С. Макаренко, которому удавалось перевоспитывать трудных подростков с помощью организации учреждений системы комлективного труда [16, с. 389].

Пенсионные системы в Европе появились раньше, чем в России и СССР, в связи с урбанизацией, развитием промышленности и, следовательно, формированием безземельного класса трудящихся. В Германии масштабные схемы социального страхования возникают в 1880-е годы [16, с. 372], в подражание им законы о пенсионном обеспечении по старости принимаются в Англии в 1908 г., где пенсионный возраст в 1908 г. составцял 70 мет [9, р. 183], а в 1946 г. - 60 мет Амя жкенщин и 65 мет Амя мужчин [9, р. 359].

Становление пенсионной системы в Советском Союзе началось с обеспечения военнослужащих - 7 августа 1918 г. вышел декрет о пенсиях Аля красноармейџев, мишившихся трудоспособности, и чменов их семей [5, с. 778-779]. 31 октября 1918 г. Положкение о социальном обеспечении трудящихся установимо пенсии по инвалидности и пособия по безработице. В 1919 г. были национализированы имперские кассы взаимопомощи.

В 1925 в СССР вводятся пенсии за выслугу цет (25 ^ет) мля работников системы народного просвещения [1, с. 92]. В 1928 г. устанавмиваются пенсии по старости Аля работников текстильной промышленности; тогда жее закрепляются пенсионный возраст и необходимый стаж на уровне 60 и 25 мет Аля мужчин и 55 и 20 мет мля женщин соответственно [17, с. 140]. Эти условия сохранялись вплоть до 2018 г., но некоторым категориям работников разрешалось выходить на пенсию по старости раньше. Средняя продолжительность жизни дия мужчин в 1928 г. составляма 36 мет, Аля женщин - 41 гол, то есть, как и в Германии при Бисмарке, смысл пенсий был скорее символическим [8, c. 58]. В 1929 г. право на пенсии по старости получили работники еще нескольких отраслей; 13 февраля 1930 г. пенсионное законодательство было консолидировано [17]. Уточнялись выплаты по инвамидности, пособия при потере кормильца, пособия на погребение. В законе также упоминались выплата пособий при родах, на предметы ухода за ребенком и на кормление ребенка. Страховые кассы могли отказать в пенсии и отправить просителей на переподготовку, были вправе выдавать пенсии и пособия натурой $[18$, с. 220-228]. Закон также оговаривал пособия по безработице, но уже в марте 1930 г. в СССР закрылась последняя биржа труда, и официально безработицы 
не было до 1991 г. [9, с. 36-48; 19]. В 1933 г. бым принят закон о распределении выпускников вузов [20, с. 701].

В Европе и США социальное страхование от безработицы появляется в начале XX в., а с 1930-х годов распространение получают пособия по безработице [9, р. 231].

Статьей 120 Конститущии СССР 1936 г. вводились равные правила по получению пенсий Аля рабочих и служащих [1, с. 95]. Крестьяне, которые вплоть до 1940-х годов составляли большинство в стране, обеспечиваци себя по принципу взаимопомощи, а декреты формализоваци этот порядок. Так, в мае 1921 г. быц принят декрет о выборных комитетах общественной взаимопомощи при сельских советах и волостных исполнительных комитетах [16, с. 319]. Комитеты были обязаны предоставлять помощь инвалидам, нетрудоспособным и нуждающимся, утратившим кормильцев; помощь при беременности; поддерживать школы, ясли, больницы; организовывать общественные работы из взносов участников касс, а с 1930 г. - колхозов [3, с. 85].

С 1936 до 1957 г. в СССР выплачивацись пособия при рождении ребенка, сначала за седьмого, а с 1944 г. - за третьего [3, с. 87] ; вначале это была разовая выплата от среднемесячной до годовой зарплаты; затем ежкемесячные платежи с 2-х Ао 4-х мет от 1/5 до одной средней заработной платы в зависимости от числа детей [21, с. 234-235]. Во Франции ежкемесячные пособия на детей начали выплачиваться с 1932 г. [16, с. 200], в Британии - с 1945 г. [9, р. 270].

Семьи военнослужкащих в годы Великой Отечественной войны были освобождены от платы за услуги ЖККХ; члены семей погибших военнослужащих получали выплаты, дети фронтовиков освобождались от платы за обучение в 8-10 классах школы, средних и высших учебных заведениях и имели приоритет при поступлении в детские сады. Были созданы системы переподготовки инвалидов войны, а также профессионального обучения Аля сирот погибших военнослужащих [4, с. 138-144].

После Октябрьской революции 1917 г. в стране выстраивалась система соџиальной политики по страховой, неэгалитарной модели, впервые примененной германским канџлером Бисмарком. Корпоративная принадлежность и «пояс» (место) проживания определяли количество и качество доступных мер поддержки. Чем более благополучным было предприятие, на котором работал гражданин, тем выше предоставлялся уровень соџиальных гарантий и качество Аоступной Аля него социальной инфраструктуры. ПреАприятия и ведомства строили свои детские сады, школы, больницы, санатории. Например, в послевоенное время только 1/6 школ на селе строилась государством, остальные финансировались колхозами [2, с. 165]. Финансирование соџиальной 
политики в СССР производицось из взносов сотруАников, среАств преАприятий, местных бюджетов и казны; управмяли этой системой органы социального обеспечения, исполкомы, профильные комиссариаты и министерства. С 1930-х годов вся ответственность за пенсии была передана от Совета социацьного страхования при Наркомате труда Центральному совету профсоюзов [4, с. 127-138]. Размер взносов устанавливался централизованно Аля разных отраслей, в среднем он составлял около $10 \%$ от зарплат [1, с. 12]. Пенсии в первой половине XX в. в СССР были низкими - 10-30\% от средней зарплаты, существовать без помощи родных большинство пенсионеров не могло [3, с. 91]. По общему уровню благосостояния советские граждане отставаци от европейцев, но развитие мер соџиальной политики шло соизмеримыми темпами с общеевропейским уровнем.

В послевоенные годы начинается масштабное реформирование системы социальной политики в СССР, приближение ее к британской, эгалитарной модели, созданной в 1940-е годы на основе доклада экономиста У. Бевериджа. Немеџкая, а по ее примеру и французская система социальной защиты использовали страховые взносы сотрудников преАприятий дия выплаты пенсий, пособий и оплаты медицинских услуг и представцяла собой совокупность множества субъектов, работающих по общим правилам. В британской системе использовались общегосударственные схемы финансирования пенсий и зАравоохранения с использованием не только взносов, но и налоговых доходов бюАжета, а учреждения вкАючались в единую административную структуру. В СССР в 1950-е годы происходит перехоА от производственного типа организации медицинских учреждений к территориальному [2, с. 174]. В июле 1956 г. постановление Верховного Совета СССР о всеобщем пенсионном обеспечении гарантировало пенсию и ее размер по старости, по инвацидности и по утрате кормицьца в зависимости от зарплаты, стажа и условий работы. Если в 1940 г. пенсию получали 3 млн человек, то в 1959 г. - 20 млн, а средний размер пенсионных выплат по отношению к средней зарплате удвоился [3, с. 215-216]. Колхозники получили госуАарственные пенсии только десять цет спустя, по закону от 15 июля 1964 г. [1, с. 168]. Пенсии составцяли около $30 \%$ от среАних зарплат, а Аля колхозников из-за сложностей с учетом трудового стажа - около 15\%. Такая система существоваца впцоть до 1980-х годов, пока они не были приближены к среднему уровню [3, c. $228-230]$.

В 1950-е годы в СССР, как и в Британии, Германии и Франџии, начинается массовая кампания строительства беспиатного жилья Аця

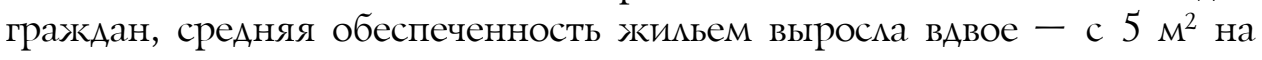


человека [3, с. 292] до $12 \mathrm{~m}^{2}$ к 1970-м годам [3, с. 310]. В 1960-е годы были кодифицированы вводившиеся с 1920-х мьготы на проезА и оплату услуг ЖКХ, в основном они распространялись на инвацидов, военнослужащих и учащихся [3, с. 105]. В 1970-е годы сформировамась система сощиального обслуживания; дия наименее обеспеченных гражАан услуги соцработников по помощи в быту предоставцялись бесплатно $[19$, с. 96]. В Германии подобный закон о сощиальной помощи был принят в 1961 г. [16, с. 272]. В Британии задача предоставления социальной помощи была решена с помощью серии законов в 1970-е годы о выплатах инвалидам Амя компенсации расходов на обеспечение мобильности и помощи соџиальных работников [22, р. 64-65] .

В Конституции СССР 1977 г. закрепцялось право граждан на материальное обеспечение в старости, при нетрудоспособности, потере кормильца, а также на бесплатное образование, медобслуживание и жилье. Исследователи пришли к выводу, что в 1970-е годы советская система стала кучшей в мире по уровню сощиальной поддержки с точки зрения равенства, доступности и объема предоставляемых ускуг [2, с. 21-23]. Посме топливного кризиса 1970-х годов на Западе приостановицось расширение социальных программ. Распространение неоконсервативной идеологии в Британии и США приводит к тому, что государство предпринимает попытки передать соџиальные функции частному сектору Аця повышения эффективности и реформирует социальную политику таким образом, чтобы приучить граждан опираться на собственные силы. В частности, в Британии изменяется метод поддержки студентов, фактически высшее образование перестает быть беспиатным [13, р. 94], пособия по безработиџе предоставцяются только тем гражданам, кто ищет работу [9, р. 315], значительно снижаются темпы индексации пенсий [9, р. 308].

Система соџиальной политики в СССР - важнейшее достижение советского периода истории. Советские и западные решения влияли Аруг на Аруга: Британия в 1940-е годы создала государство всеобщего благосостояния дия предотврашения распространения коммунистической идеологии, а СССР в 1950-е годы перенял британскую систему массового жилищного строительства и всеобщего пенсионного обеспечения, которые стали наиболее удачными и популярными мерами социальной поддержки в Советском Союзе. Ряд решений СССР в сфере трудового законодательства и здравоохранения был передовым на мировом уровне. Советское заравоохранение стало первой в мире всеобшей и бесплатной системой.

У. Беверидж при разработке теории государства всеобщего бцагосостояния рассчитывац циквидировать безработицу. В СССР всеобщая 
занятость была достигнута, бирж труда не сушествовало с 1930 г., благодаря системе распределения специалистов после обучения выпускникам не нужно было искать работу. Советская система изначально выстраивацась в цогике корпоративного немеџкого подхода с отде-

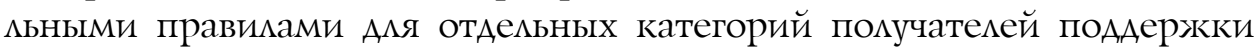
и большим участием преАприятий в их предоставлении, но затем усвоила солидаристские и эгалитаристские британские принщипы, это сочетание сохранилось в России и после преобразований в 1990-е годы. Неоконсервативное сокращение и приватизаџия соџиальной политики на Западе в 1980-е годы изучались в России и послужкили примером Аля ряда преобразований.

Советская система соџиальной политики формировалась парамлельно с западным «государством всеобщего благосостояния»; некоторые меры принимахись раньше, чем в Европе и США, а некоторые заимствовацись из западного опыта или применялись одновременно с ними. Охват мерами поддержкки и доступность беспиатных услуг в СССР постепенно возрастал в период с 1917 по 1956 г., а посме 1956 г. все граждане страны получили право на пенсионное обеспечение, бесплатное высшее образование, массово предоставцялось жилье, с 1970-х годов были введены бесплатные услуги соџиальных работников дмя инвалиАов. Похожие права имели граждане западных «государств всеобщего благосостояния», но реализация этих прав чаще всего осуществцялась иначе - не как бесплатное предоставление услуг, а в виде пособий на

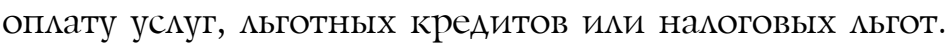

Наиболее значимые советские решения сохранились в современной России - беспиатное образование, здравоохранение, всеобщее пенсионное обеспечение, оплачиваемый отпуск Аля беременных. Эти достижения имеют большое значение в обеспечении соџиальной и экономической стабильности, увеличивая покупательную способность граждан и гарантируя им прожиточный минимум. Западное «государство всеобщего благосостояния» не утратило свою структуру после преобразований 1980-х годов и до сих пор остается моделью для подражания при развитии систем соџиальной политики. В России целесообразно учитывать западный опыт по оптимизации нагрузки социальных расходов на бюджет и не отказываться от положительных элементов сложившейся системы соџиальной политики.

\section{Библиографический список}

1. Андреев В.С. Право социального обеспечения в СССР: учебник. М., 1980.

2. Советская социальная политика: сцены и действующие лица, 1940-1985 / под ред. Е.Р. Ярской-Смирновой, П.В. Романова. М., 2008. 
3. Гуменюк A.A. Социальная стратегия Советского государства и практики повседневности населения российской провинции во второй половине 1950-х - середине 1980-х гг.: на материалах Нижнего Поволжья: дис. ... д-ра ист. наук. Саратов, 2019.

4. Кононова Т.Б. История социальной работы: учебник для бакалавров. М., 2014.

5. Собрание узаконений и распоряжений правительства за 1917-1918 гг. М., 1942.

6. Parental Leave and Beyond: Recent International Developments, Current Issues and Future Directions / ed. вy P. Moss, A.-Z. Duvander, A. Koslowski. Bristol: Policy Press, 2019.

7. Большая медицинская энциклопедия: в 30 т. / гл. ред. Б.В. Петровский. 3-е изд. M., 1978. T. 8.

8. Андреев Е.М., Дарский Л.Е., Харькова Т.Л. Население Советского Союза, 19221991. M., 1993.

9. Fraser D. The Evolution of the British Welfare State. Basingstoke: Palgrave Macmillan. 2009.

10. Константинов Н.А., Медынский Е.Н., Шабаева М.Ф. История педагогики. 5-е изд., доп. и перераб. М., 1982.

11. Кораблева Г.В. Реализация принципов доступности и бесплатности образования в советском государстве (1917-1991 гг.) // Известия Самарского научного центра Российской академии наук. 2009. Т. 11, № 6(2). С. 341-345.

12. The Oxford Handbook of the History of Education / ed. by J.L. Rury, E.H. Tamura. Oxford: Oxford University Press, 2019.

13. Towards the Private Funding of Higher Education: Ideological and Political Struggles / eb. by D. Palfreyman, T. Tapper, S. Thomas. London: Routledge, 2017.

14. Дошкольная педагогика / под ред. В.И. Ядэшко, Ф.А. Сохина. М., 1978.

15. The Development of Early Childhood Education in Europe and North America. Historical and Comparative Perspectives / ed. by H. Willekens, K. Scheiwe, K. Nawrotzki. Basingstoke: Palgrave Macmillan, 2015.

16. Фирсов М.В. История социальной работы: учебное пособие. М., 2012.

17. Фирсов М.В. История социальной работы в России: учебное пособие. М., 1999.

18. Собрание законов и распоряжений Рабоче-Крестьянского Правительства СССР за 1930 год. М., 1930.

19. Лушникова М.В., Лушников А.М. Курс права социального обеспечения. 2-е изд., доп. М., 2009.

20. Собрание законов и распоряжений Рабоче-Крестьянского Правительства СССР за 1933 год. М., 1948 г.

21. Сборник законов СССР и указов Президиума Верховного совета СССР. 1938 1944 гг. М., 1945.

22. Hood A., Norris Keiller A. A Survey of the UK Benefit System. London: IFS, 2016. 